\title{
P20 MAKING VOLUNTEERS COUNT
}

Ros Scott Childrens Hospice Association Scotland, Edinburgh, UK

10.1136/bmjspcare-2011-000105.20

Background Many hospices owe their origins to volunteers. Volunteers' involvement today is still integral and vital to the success of the hospices they support. However the strategic importance of volunteers is often overlooked and the role of volunteers and their contribution to the cost effectiveness and sustainability of hospices is rarely considered. However if volunteers are to be fully recognised as a strategic asset we must be brave enough also to describe volunteers in business terms.

Purpose of project The purpose of the project is to:

- Determine the economic value of volunteers and return on investment

- Demonstrate volunteering as a strategic asset.

- Explore the use of the economic value of volunteers to influence funders.

Methods Volunteer hours may be collected in many different ways depending on the way volunteering is structured. Hours are calculated on a monthly basis and recorded on a spreadsheet. Staff equivalent roles and hourly rates are then listed for each volunteer role. These are then multiplied by the number of volunteer hours and a percentage added for on costs. Once the total has been calculated the return on investment can be calculated.

One hospice's experience Volunteer value in CHAS is calculated and reported on an annual basis. In the year 2009-2010, 900 volunteers donated $83,100 \mathrm{~h}$, with an economic value of $£ 1.25 \mathrm{~m}$. The return on investment was 7:1. The information is disseminated in many ways and is used for many purposes, including as part of the charity's annual report.

Conclusions In this time of challenging and uncertain economic circumstances, measuring the value of volunteer time has many benefits to hospices and can be used in many ways. These include monitoring and demonstrating the cost effectiveness of services and influencing funders. 